\title{
Potencialidades da rede social Facebook como um espaço complementar à sala de aula durante estudo de sólidos geométricos: discutindo de um produto educacional
}

\author{
Potentialities of the social network Facebook as a complementary space to the \\ classroom during the study of geometric solids: discussing of an educational \\ product
}

\section{Resumo}

Com o objetivo de apresentar contribuições do produto educacional intitulado Geometria nas redes sociais: curta essa ideia! como material suporte para o professor, este artigo versa sobre o guia didático resultante de uma pesquisa de mestrado que teve como principal objetivo analisar as habilidades do pensamento geométrico construídas por alunos do ensino médio a partir de interlocuções propiciadas pela interação em sala de aula e em redes sociais, durante o estudo de sólidos geométricos. A pesquisa foi realizada com 89 alunos da terceira série do ensino médio durante o ano de 2014, tendo como suporte teórico os trabalhos de Marcelo Bairral, sobre interações em ambientes virtuais, a teoria de Van Hiele, sobre ensino e aprendizagem de geometriae as concepções de Gutiérrez sobre a visualização. Constatamos a importância de aspectos visuais para a aprendizagem geométrica e a potencialidade do uso das redes sociais aliadas ao trabalho desenvolvido em sala de aula, indicativos que são compartilhados com os professores que estão em sala de aula por meio do guia didático produzido.

Palavras-chave: Guia Didático. Sólidos Geométricos. Facebook. Interação.

\section{Abstract}

With the objective of presenting contributions of the educational product titled Geometry in social networks: short this idea! as a support material for the teacher, this article deals about the didactic guide resulting from a master's research which had as main objective

\footnotetext{
${ }^{1}$ Mestra em Educação em Ciências e Matemática pelo Instituto Federal do Espírito Santo (IFES). Professora de Matemática da Secretaria de Estado da Educação do Espírito Santo (SEDU). E-mail: organdimongin@hotmail.com

${ }^{2}$ Doutora em Educação pela Universidade Federal do Espírito Santo (UFES). Professora do Programa de Mestrado Profissonal em Educação em Ciências e Matemática (Educimat) e da Licenciatura em Matemática do Instituto Federal do Espírito Santo (IFES), Campus Vitória. E-mail: sandrafraga7@ gmail.com
} 
analyze the geometric thinking abilities built by high school students from the interlocutions provided by the interaction in the classroom and in social networks during the study of geometric solids. The research was carried out with 89 students of the third year of high school during the year 2014, with the theoretical support of Marcelo Bairral's work on interactions in virtual environments, Van Hiele's theory on teaching and learning geometry, and Gutiérrez's conceptions about visualization. We note the importance of visual aspects for the geometric learning and the potentiality of the use of social networks allied to the work developed in the classroom, indicatives that are shared with the teachers who are in the classroom through the didactic guide produced.to classroom work, indicatives that are shared with teachers who are in the classroom through the didactic guide produced.

Keywords: Didactic guide. Geometric solids. Facebook. Interaction.

\section{Introdução}

Novas relações que podem ser estabelecidas com o saber, na atualidade, nos fazem pensar na utilização de diferentes tecnologias. Contudo, a compreensão de tecnologia não deve limitar-se a aparatos eletrônicos. Giz, caderno, quadro e livro também são tecnologias, porém, são tradicionais. Mais recentes, contudo, temos as tecnologias provenientes da utilização do computador, como por exemplo, a internet, os softwares e os espaços virtuais de comunicação (blogs, chats, redes sociais etc.).

Segundo Borba, Silva e Gadanidis (2014), desde a implantação de laboratórios de informática em escolas, alguns momentos marcaram a utilização das tecnologias digitais na educação matemática, dentre eles: a utilização das calculadoras comuns, das científicas e dos softwares voltados para a representação das funções e da geometria dinâmica; a utilização da internet como fonte de informação e comunicação e o surgimento dos ambientes virtuais de aprendizagem. Este último, representa o atual momento que estamos vivendo, marcado pela utilização da internet rápida, acessada não somente pelo computador e utilizada para a interação e para a comunicação, no qual as redes sociais ganham cada vez mais espaço. 
Não há como ignorar a influência que as redes sociais exercem na vida das pessoas, em especial na dos mais jovens. Diante disso, surge o questionamento: porque não utilizar esses ambientes para enriquecer o processo de ensino e aprendizagem? Por meio da utilização de redes sociais, por exemplo, o aluno pode multiplicar o conhecimento para sua teia social e o professor, por sua vez, utilizar a plataforma como um canal para compartilhar informações, acessar vídeos e outros instrumentos que não são possíveis em sala de aula e, assim, aprofundar os temas que lá foram discutidos.

Nessa perspectiva, desenvolvemos uma pesquisa de mestrado, Rovetta (2015), que objetivou analisar as habilidades do pensamento geométrico construídas por alunos do ensino médio a partir de interlocuções propiciadas pela interação em sala de aula e em redes sociais, durante o estudo de sólidos geométricos. A pesquisa propôs, assim, a utilização pedagógica de redes sociais, especificamente o Facebook, como um espaço complementar à sala de aula, visando estabelecer uma relação entre o ambiente presencial (sala de aula) e o ambiente virtual (rede social), a fim de propiciar a interação entre os envolvidos, além de oportunizar a utilização de outros recursos multimídias.

Durante essa pesquisa, elaboramos um guia didático, compartilhando nossa experiência e trazendo propostas de trabalho que visavam integrar os dois ambientes estudados: a sala de aula e a rede social. Nele, apresentamos algumas atividades que foram desenvolvidas em cada ambiente, destacando como elas podem contribuir para a construção de importantes habilidades relacionadas à construção do pensamento geométrico.

Kaplún (2013) orienta que a criação de um material educativo requer conhecer a fundo a matéria em questão, bem como os conceitos que a articulam. O autor explica, ainda, que "depois disso será preciso escolher as ideias centrais que serão abordadas pelo material, bem como o tema ou temas principais através dos quais se procurará gerar uma experiência de aprendizado" (KAPLÚN, 2003, p. 48). Procuramos, assim, construir um material educativo tendo esses cuidados. 
O guia didático, que será detalhado mais adiante neste texto, tem como propósito mostrar possibilidades de trabalho para que, a partir do que foi apresentado, os professores criem outras atividades e possibilidades de trabalho. Não se trata de um material "engessado" e com receitas prontas, mas de uma sequência de atividades planejadas intencionalmente sobre sólidos geométricos, aplicada em turmas de terceiro ano do ensino médio de uma escola pública do interior do Espírito Santo.

Sendo assim, o objetivo deste artigo é apresentar as contribuições do produto educacional criado por Rovetta e Silva (2015) como um material que possa servir de inspiração para a criação de novas atividades, bem como discutir os resultados da pesquisa de mestrado realizada, aproximando o professor da pesquisa científica.

Iniciamos o texto fazendo uma breve discussão sobre as teorias que embasaram o trabalho. Na sequência, discorremos sobre a pesquisa de mestrado que subsidiou a construção do guia didático. Como ponto central deste artigo, apresentamos o guia didático "Geometria nas redes sociais: curta essa ideia!"3 (ROVETTA; SILVA, 2015) e suas potencialidades e finalizamos com algumas reflexões sobre a pesquisa realizada e sobre o material produzido.

\section{As bases teóricas da pesquisa}

Propomos uma breve discussão teórica sobre a fundamentação da pesquisa, que teve dois pontos centrais: o ensino de geometria e de tecnologias da informação e a comunicação no contexto da educação matemática.

A escolha pelo conteúdo matemático sólidos geométricos se deve à preocupação com a abordagem escolar dada à geometria, visto que a predominância do raciocínio algébrico-geométrico, em detrimento de atividades

\footnotetext{
${ }^{3}$ Disponível em:

http://educimat.ifes.edu.br/images/stories/Publica\%C3\%A7\%C3\%B5es/Produtos\%20Edu cacionais/2015-PE-GDM23-Organdi-Mongin-Rovetta.pdf
} 
que exploram a visualização, ainda está presente em grande parte das nas escolas.

Nesse sentido, recorremos à teoria de Van Hiele, que explica a construção do pensamento geométrico a partir de níveis. Embasamo-nos na forma como essa teoria explica a construção do pensamento geométrico dentro de cada nível e destacamos a importância da visualização.

No que diz respeito às tecnologias da informação e comunicação, recorremos aos trabalhos de Bairral $(2007 ; 2009)$ sobre as relações de interação em ambientes virtuais.

\subsection{0 ensino de Geometria}

Segundo Nacarato e Santos (2014), o ensino de geometria no Brasil ainda está longe do adequado, pois a forma como os conceitos são explorados nem sempre favorece a sua aprendizagem. É comum encontramos, ainda hoje, práticas educacionais centradas num modelo reducionista, com foco no ensino da geometria plana, por meio de nomenclaturas e fórmulas.

Ainda há muito o que fazer para que esse conteúdo seja trabalhado de maneira mais adequada em sala de aula. Destacamos dois pontos importantes que merecem atenção: refletir sobre o processo de ensino e aprendizagem da geometria e sobre as possibilidades de trabalho em sala de aula; e, compreender como ocorre a construção do pensamento geométrico.

Sendo assim, chamamos atenção para um casal de professores holandeses, Pierre Van Hiele e Dina Van Hiele-Geoldof, que se incomodava com o fato de os alunos não aprenderem geometria e decidiram pesquisar os motivos, criando, assim, uma teoria para a construção do pensamento geométrico, chamada Teoria de Van Hiele.

De acordo com essa teoria, alunos apresentam modos diferentes de pensar e raciocinar geometricamente, o que pode acontecer também com os 
alunos, entre eles e, ainda, entre os alunos e os professores. A teoria organiza uma maneira de compreender a construção do pensamento geométrico em cinco níveis hierárquicos: visualização, análise, dedução informal, dedução formal e rigor. O progresso entre os níveis é determinado pela aprendizagem satisfatória do nível anterior. Reconhecemos (e concordamos) que a questão da hierarquia entre os níveis vem sendo criticada em pesquisa mais recentes, porém, compreendemos a importância dessa teoria em diversos aspectos, dentre os quais, com a questão sobre diferentes aspectos da construção do pensamento geométrico partindo da visualização, que é o foco do nosso trabalho.

Para isso, complementamos nossas discussões acerca do ensino de geometria recorrendo às concepções de Angel Gutiérrez, pesquisador espanhol que compreende a visualização na matemática como um tipo de atividade de raciocínio baseada no uso de elementos visuais, sejam mentais, sejam físicos, para resolver problemas ou provar propriedades, de acordo com Gutiérrez (1996).

Reforçamos a importância de o professor propor atividades que desenvolvam certas habilidades visuais e que o mesmo acompanhe a evolução de habilidades referentes à utilização de representações técnicas, visando evitar um acúmulo de dificuldades e um possível bloqueio com a geometria.

Diante disso, entendemos que as tecnologias podem contribuir nesse processo. Sobre as tecnologias a favor da educação trazemos uma discussão sobre $o$ assunto na sequência do texto.

\subsection{Utilização das tecnologias da informação e comunicação no contexto da educação matemática}

Os autores Borba, Silva e Gadanidis (2014) explicam que as fases que marcaram as tecnologias digitais na educação matemática não são independentes, sendo cada uma delas uma ampliação da anterior, porém com suas particularidades.

Diante das mudanças na forma de comunicação decorrentes da tecnologia, 
a relação professor/aluno/conhecimento ganha uma nova dinâmica, assumindo, desse modo, um papel colaborativo. O dinamismo que as redes sociais possibilitam pode ser destacado como um fator positivo da utilização desses ambientes virtuais na educação. Propusemos assim, em nosso trabalho de pesquisa, discutir as relações de interação possibilitadas pelos ambientes virtuais e a maneira como esses espaços podem contribuir para a aprendizagem matemática.

Segundo Bairral (2009), quatro características essenciais são atribuídas à informática educativa: conectividade, integração de mídias, dinâmica e construção hipertextual e interatividade. A possibilidade de integração de mídias foi um dos fatores que nos levaram a escolher a rede social Facebook, como ambiente virtual, para desenvolver a pesquisa.

O aprendizado matemático se desenvolve, de acordo com Bairral (2007), mediante o discurso, a interação e a relação mútua entre esses dois campos subsidiando uma reflexão sobre como pensar atividades matemáticas. Sendo assim, a produção escrita oriunda dos ambientes virtuais pode ser um campo fértil para o professor analisar potencialidades e dificuldades no processo de ensino e aprendizagem de matemática.

De acordo com Bairral (2007), a escrita virtual é construída por interlocutores que, num determinado espaço comunicativo, interagem por meio de práticas discursivas: as interlocuções. Salles e Bairral (2012) explicam que as interlocuções consistem num discurso em que são analisadas diferentes formas de participação, ocorridas em unidades de conversas, sejam interações orais, sejam as escritas.

Analisar interlocuções em discursos on-line possibilita acompanhar mudanças que vão ocorrendo durante a construção do conhecimento matemático por parte dos alunos. Desse modo, na análise do processo interativo podemos obter informações que auxiliariam na intervenção da aprendizagem do interlocutor alvo da pesquisa. Além disso, ela permite investigar como os sujeitos compartilham significados e conceitos. Essa nossa análise, Rovetta (2015), será 
apresentada na seção seguinte.

\section{Sobre a pesquisa de mestrado que subsidiou a elaboração do produto educacional}

A pesquisa de mestrado, que subsidiou a produção do produto educacional que vamos discutir neste artigo, foi realizada em uma escola da rede estadual de ensino do Espírito Santo, com quatro turmas de $3^{\circ}$ ano do ensino médio. Ao todo, 89 alunos participaram, efetivamente, da investigação.

O foco da prática desenvolvida com os alunos foi integrar dois ambientes de aprendizagem: a sala de aula (ambiente presencial) e um grupo criado no Facebook (ambiente virtual). O diferencial desta pesquisa encontra-se no fato de que os ambientes não foram estudados isoladamente, mas como espaços complementares, de forma que as atividades desenvolvidas em cada um se integravam. O ambiente virtual ficou caracterizado, dessa forma, como uma extensão da sala de aula, com a finalidade de interação e comunicação, tendo como base discussões realizadas presencialmente nas aulas de matemática. Algumas discussões começavam em sala de aula e se estendiam para o ambiente virtual; outras tinham como base uma postagem no ambiente virtual, cuja discussão se estendia à sala de aula.

A dinâmica era a seguinte: no ambiente presencial eram desenvolvidas atividades diferenciadas envolvendo, principalmente, os dois primeiros níveis da teoria de Van Hiele: visualização e análise. Paralelamente, no ambiente virtual, eram propostas atividades sobre sólidos geométricos, por meio de vídeos e plataformas, que permitiam trabalhar com geometria dinâmica, resolução e discussão de problemas envolvendo visualização e a postagem dos materiais produzidos.

É importante pontuar que o acesso ao ambiente virtual ocorreu fora da escola, pois o acesso às redes sociais não era liberado pelo servidor de internet do local. Assim, cada aluno, em sua residência, acessava, por computador ou celular, o Facebook. 


\section{Organização e estrutura do produto educacional}

A ideia de sistematizar um produto educacional por meio do qual pudéssemos compartilhar com outros professores de Matemática a experiência desenvolvida ao longo da pesquisa, partiu da observação de que a investigação realizada foi uma experiência rica e inovadora para a educação matemática. É comum encontrarmos pesquisas que discutem a questão da utilização das redes sociais no contexto da educação, porém trazemos uma nova roupagem para essa questão, que é a utilização do ambiente virtual como um complemento ao ambiente presencial, estabelecendo uma relação entre esses dois espaços, de forma que aprendizagens desenvolvidas em cada ambiente tenham relação com o outro.

Ressaltamos que tomamos alguns cuidados na produção do material, buscando orientação nos eixos apresentados por Kaplún (2003) para construção de mensagens educativas. Segundo ele, o material educativo é um objeto que facilita a experiência de aprendizado ou, ainda, mediada para o aprendizado. Dessa forma, o autor chama a atenção para três eixos, base para análise e construção de mensagens educativas. São eles: conceitual, pedagógico e comunicacional.

Sobre o eixo conceitual, Kaplún (2003) explica que é importante conhecer a fundo a matéria em questão, bem como os conceitos que a articulam, antes de construir um material. Esse conhecimento prévio é importante para que, depois, seja possível estruturar as ideias centrais do material.

O eixo pedagógico representa o ponto principal do material educativo. Para Kaplún (2003), esse eixo implica em uma análise dos destinatários da mensagem, propondo identificar um ponto de partida e um ponto de chegada, de forma que esse trajeto enriqueça algumas concepções, percepções e valores.

Por fim, o eixo comunicacional representa, de acordo com Kaplún (2003), um articulador dos outros dois eixos, trata-se de percorrer o caminho traçado no eixo pedagógico e de rever algumas das definições anteriores. 
Por ser tratar de uma pesquisa de mestrado, antes mesmo de pensarmos na sistematização do guia didático, fizemos uma revisão de literatura sobre trabalhos com a temática próxima à nossa. Além disso, aprofundamos em leituras sobre os referenciais teóricos utilizados, buscando, assim, conhecer melhor o conteúdo.

Durante a pesquisa, recorremos a algumas publicação/livros do Projeto Fundão (SEGADAS, 2008; NASSER; TINOCO, 2011) ${ }^{4}$ como fonte de pesquisa para a elaboração das atividades de geometria realizadas nos dois ambientes estudados. O material produzido pelo Projeto Fundão apresenta resultados de trabalhos de pesquisa, bem como ações de formação e de apoio a professores. Segadas (2008), por exemplo, traz atividades comentadas sobre visualização de figuras espaciais; já Nasser e Tinoco (2011), além das discussões teóricas sobre a Teoria de Van Hiele apresentam, também por meio de atividades comentadas, questões sobre a formação de conceitos geométricos.

Ao explorarmos alguns desses livros do Projeto Fundão, elaboramos grande parte das atividades que foram realizadas com os alunos, nos dois ambientes, durante a pesquisa. Os livros serviram, assim, de apoio e inspiração para nossas atividades. Dessa forma, foi a partir da experiência positiva em trabalhar com esse material, que pensamos no nosso produto educacional: produzir um material, nessa linha de trabalho, para o professor de Matemática.

O material que utilizamos, do Projeto Fundão, nos ajudou a pensar na estrutura da nossa produção, direcionado o caminho a ser percorrido pela pesquisa de mestrado. As análises dos dados da pesquisa realizada no mestrado proporcionaram reflexões sobre conceitos e sobre a prática do professor, reflexões estas, que trazemos por meio de comentários e questionamentos no guia didático. Estabelecemos, assim, relação com os eixos pedagógico e comunicacional, postulados por Kaplún (2013).

A partir desta perspectiva, produzimos um guia didático destinado aos professores de Matemática do ensino médio, cujas atividades também podem ser

\footnotetext{
${ }^{4}$ Projeto do Instituto de Matemática da Universidade Federal do Rio de Janeiro.
} 
utilizadas ou adaptadas para os anos finais do ensino fundamental. Conforme já mencionamos, o guia é um material de apoio para o professor, a fim de que possa também servir de inspiração para a criação de novas atividades, mediante as adaptações necessárias.

O nome "guia", em algumas situações, nos remete a algo "pronto a ser seguido", mas não é o caso do nosso produto educacional. Esse nome é o utilizado pelo programa de Mestrado Profissional em Educação em Ciências e Matemática do Instituto Federal do Espírito Santo para os produtos gerados pelas pesquisas desenvolvidas. Não elaboramos o guia didático com a intenção de dar uma receita pronta que deve ser seguida à risca. Pelo contrário, nossa proposta é que o material auxilie o professor de Matemática, contribuindo para que ele tenha um novo olhar sobre o processo ensino e aprendizagem da geometria e a utilização de redes sociais no contexto da educação.

O guia didático contém as seguintes seções: sumário, apresentação, introdução, como o trabalho foi desenvolvido, atividades comentadas, considerações finais, referências, sugestões de leituras e anexos.

Mesmo que o objetivo do guia não seja o de trazer tantas discussões teóricas, consideramos importante relatar nele como o trabalho foi desenvolvido e a dinâmica da utilização das redes sociais como um espaço complementar à sala de aula, bem como as teorias que embasaram o estudo. Por isso, na apresentação e na introdução, fazemos isso e também damos uma visão geral sobre as atividades que serão apresentadas no material.

O ponto central do produto educacional é a seção "atividades comentadas", na qual apresentamos e comentamos algumas atividades que foram desenvolvidas em cada ambiente (presencial e virtual) durante a pesquisa. Ao explorar essas atividades, relatamos como foi nossa experiência e fazemos uma rápida descrição, com orientações para sua aplicação. Além disso, após a explanação da atividade, dialogamos com o professor, fomentando algumas reflexões. Dessa forma, esperamos que o professor reflita sobre sua própria prática e perceba-se como um dinamizador do processo de ensino e 
aprendizagem. Na seção seguinte, trazemos alguns exemplos dessas atividades.

\subsection{As atividades comentadas}

Nesta parte do produto educacional, o guia didático, compartilhamos quatro atividades realizadas no ambiente presencial e duas no ambiente virtual. A proposta foi tanto apresentar as atividades quanto comentá-las e dialogar com o professor leitor, de forma a contribuir para que ele reflita sobre a própria prática, conforme já mencionamos.

Para ilustrar com mais detalhes o trabalho desenvolvido com os alunos durante a pesquisa, bem como a forma com a qual propomos compartilhar essa experiência com os professores de matemática por meio do guia didático, selecionamos uma atividade desenvolvida no ambiente presencial e sua respectiva atividade desenvolvida no ambiente virtual, para demonstrarmos, neste artigo, o trabalho que foi realizado.

Apresentamos, dessa forma, a atividade "Projeção ortogonal", desenvolvida em sala de aula e a atividade complementar a ela, "Problema Cubos Pintados", desenvolvida no ambiente virtual.

O quadro 1 mostra a apresentação da atividade "Projeção ortogonal", que foi desenvolvida no ambiente presencial.

\section{Projeção ortogonal}
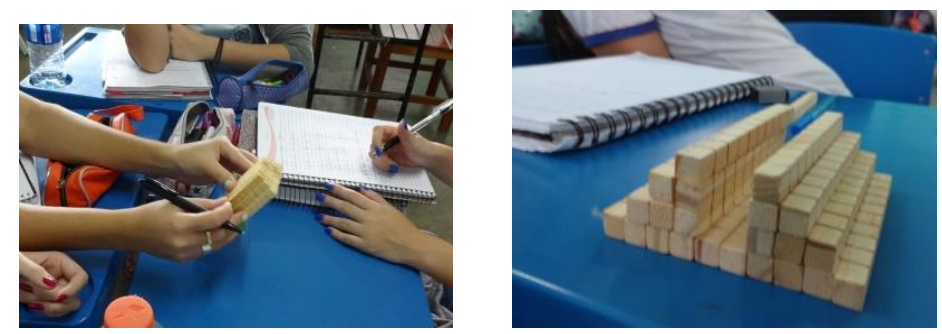

A atividade foi realizada no ambiente presencial e teve a duração de uma aula de 55 minutos. Para a realização da tarefa, os alunos deveriam, utilizando material dourado, construir blocos e fazer a representação dos mesmos no plano, por meio da projeção ortogonal (vistas) superior, frontal e lateral. Não havia um padrão para o bloco a ser construído, os alunos poderiam utilizar quantos cubinhos fossem necessários. As representações foram feitas no caderno, mas também seria interessante fazê-las na malha quadriculada.

Além do material dourado, outros recursos podem ser utilizados para a realização desta atividade, como, por exemplo, construções utilizando pequenas caixas. Outra sugestão é explorar o espaço físico da escola (bancos, escadas e objetos variados). 
Quadro 1 - Atividade realizada em sala de aula.

Fonte: adaptado de Rovetta; Silva (2015, p.24)

Nesse primeiro contato do professor/leitor com a atividade, pretendemos, de maneira simples e direta, contar como foi o seu desenvolvimento, relatar a nossa experiência, mostrando, também, outras possibilidades de aplicação.

O quadro 2 dá continuidade à atividade anterior, trazendo um comentário no espaço virtual, sobre nossas percepções a realizar a atividade do quadro 1 em sala de aula.

\section{Comentário:}

De maneira geral, os alunos não apresentaram dificuldade em construir a projeção ortogonal superior, porém não tiveram a mesma facilidade para construir as projeções ortogonais frontal e lateral.

Quadro 2 - Comentário sobre a atividade do quadro 1.

Fonte: Rovetta; Silva (2015, p.24)

Para finalizar, propomos uma reflexão sobre a prática desenvolvida e questionamos novas possibilidades a partir dela (quadro 3). Como o contexto das atividades no ambiente virtual é a rede social Facebook, utilizamos caracteres mais descontraídos ao longo do guia didático, fazendo referência à essa rede social.

\section{Status Foto/Vídeo $\nabla$ Acontecimento}

Professor, trabalhar com fotografia pode ser uma proposta interessante. Além de auxiliar no trabalho sobre projeção ortogonal, pode ser um bom recurso para discutir perspectiva. Você já deve ter visto alguns tipos de fotos na qual se aplica uma técnica fotográfica onde se busca alterar as proporções naturais entre os objetos enquadrados. Para isso, os objetos menores são colocados num primeiro plano de modo que pareçam maiores que os objetos realmente maiores colocados num plano de fundo. Essa técnica é conhecida como perspectiva forçada. Que tal propor que os alunos produzam fotos desse tipo? Mediante essas fotos, o que poderia ser explorado com os alunos?

아 49 (ㄴ) 8 Amigos v Publicar

Quadro 3 - Reflexão para o professor/leitor do guia didático. 
Fonte: Rovetta; Silva (2015, p.25)

Para cada atividade que apresentamos no guia didático, seja ela desenvolvida no ambiente presencial ou virtual, a sequência utilizada foi: apresentar a atividade, comentar nossas impressões e, posteriormente, propor uma reflexão para o professor/leitor.

Dessa forma, logo após a atividade, por meio de um comentário, fazemos um breve relato da nossa experiência. Finalizamos cada atividade com uma caixa de texto, em que dialogamos com o professor e refletimos sobre a importância da atividade apresentada, no contexto da aprendizagem geométrica. Além disso, deixamos um questionamento para que o professor/leitor amplie sua análise e pense em novas possibilidades.

Dando continuidade, a atividade seguinte (quadro 4) foi desenvolvida no ambiente virtual. Trata-se de um problema, por meio do qual os alunos interagiram e buscaram, coletivamente, a resolução.

\section{Problema: "Cubos pintados"}

Esta atividade foi realizada no ambiente virtual, publicada como anexo em arquivo de Word. Trata-se de um problema cuja resolução envolve habilidades de visualização.

Por meio dos comentários, os alunos interagiram e discutiram, manifestando-se através de diferentes tipos de interlocuções (que são práticas discursivas orais ou escritas), sendo que algumas delas nos possibilitaram analisar habilidades presentes na construção do pensamento geométrico e, em outros casos, a carência de algumas dessas habilidades.

Na figura abaixo, apresentamos um desses problemas, chamado de cubos pintados e algumas interações dos alunos visando resolvê-lo.

\section{CUBOS PINTADOS}

Dezesseis cubos de $1 \mathrm{~cm}$ de lado são colocados juntos, formando o paralelepípedo representado abaixo

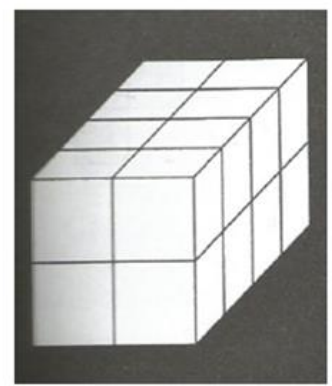

A superficie do mesmo foi pintada de verde e, em seguida, os cubos foram separados. Qual o número de cubos com exatamente duas faces verdes?

Referência: SEGADAS, C. (coor.). Visualizando Figuras Espaciais. Rio de Janeiro: IM/UFRJ, 2008. 
Quadro 4 - Problema postado no ambiente virtual.

Fonte: Adaptado de Rovetta;Silva (2015, p. 25-26)

Conforme descrito, a atividade foi veiculada em forma de anexo no formato Word. Os alunos, após analisarem, deveriam postar suas respostas, utilizando a ferramenta comentário.

Chamamos atenção para um diálogo realizado entre alguns alunos (quadro 5), cujos nomes utilizados são fictícios, devido a questões de ética de pesquisas com seres humanos.

Interações de alguns alunos:

B Janaina: serão 8 cubinhos com duas faces verdes, pois os outros serão de uma ou três faces pintadas.

is Euller: exato, os quadrados pintados que estão no meio do paralelepípedo são os que terão 2 faces pintadas, ou seja, oito, porem só para fazer uma correção Janaina acredito que não haverá quadrados com apenas uma face pintada.

i Janaina: Depende, se a parte de baixo também for pintada, realmente não terão quadrados com apenas uma face pintada.

i Jair: Também concordo que seja oito quadrados assim como os outros, pois ao pintarmos a superfície só os cubos do meio é que ficarão com duas de suas faces pintadas de verde. Os do canto terão três faces pintadas de verde. Portanto nenhum dos cubos terão apenas uma face pintada viu Janaina.

is Janaina: Tá ok. Apenas interpretei de outro jeito! Kkkk

B Euller: se a parte de baixo não for pintada o resultado vai ser 8, porem vai haver quadrados com só um lado pintado.

B Janaina: Disso que eu tava falando kkk

B Jair: Mas a parte de baixo também é superfície, só para lembrar.

B Euller: porem Jair depende da interpretação, pois se consideramos a superfície como todos os lados que se pode ver em qualquer situação seu pensamento esta correto, porem se imaginarmos q superfície representa os lados visíveis no momento então o "Teorema da Janaina" está correto.

Quadro 5- Interações dos alunos na resolução do problema "cubos pintados".

Fonte: Rovetta; Silva (2015, p. 26-27).

Observamos, no diálogo, alguns pontos importantes durante o processo de construção do pensamento geométrico e, por meio de comentário sobre nossas 
percepções (quadro 6), discutimos esses pontos com o professor/leitor.

\section{Comentário:}

No diálogo anterior, os quatro alunos interagem mutuamente buscando a solução de outra questão: a possibilidade de haver cubinhos com uma única face pintada de verde. A discussão surgiu a partir da resposta da aluna Janaína, que além de responder o questionamento feito (dizer quantos cubinhos com duas faces verdes haveria), analisou quantos teriam uma ou três faces pintadas. A discussão é riquíssima para que o professor possa analisar algumas habilidades do pensamento geométrico construídas pelos alunos. Obviamente determinados tipos de interlocuções nos permitem fazer uma análise indo além daquilo que está escrito, como foi o caso. Podemos perceber, por exemplo, que ainda há uma confusão entre plano e espacial, pois em alguns momentos eles se referem aos cubinhos como quadrados e as faces como lados. Por meio desse processo interativo, os próprios alunos perceberam que a questão levantada pela Janaína a respeito de haver cubinhos com apenas uma face pintada, ocorreu pelo fato dela não considerar uma das superfícies, no caso, a que estava apoiada sobre o plano horizontal.

Quadro 6 - Comentário sobre as interações dos alunos.

Fonte: Rovetta; Silva (2015, p.27).

Finalizamos essa parte da atividade com algumas reflexões para 0 professor/leitor (quadro 7), destacando a importância da escrita para a aprendizagem matemática.

Status Foto / Vídeo $\nabla$ Acontecimento

Professor, a escrita também é um importante instrumento para a aprendizagem matemática, pois possibilita examinar o desenvolvimento do pensamento matemático. A reflexão sobre a matemática, possibilitada por meio da escrita, leva os alunos a importantes avanços cognitivos e afetivos. Obviamente alguns alunos não interagiram com os colegas e se limitaram a responder: "8 cubinhos" e isso também caracteriza um tipo de interlocução, que por sua vez não nos permite a riqueza de análise como as apresentadas anteriormente. O caminho até este nível de interação e aprendizagem entre os alunos é longo. É preciso que o professor estimule a participação, fomente as discussões e que o aluno perceba-se como uma peça fundamental no seu processo de aprendizagem. O processo dialógico de aprendizagem pode contribuir para isso. No início as interações dos alunos eram muito tímidas e poucos comentavam as atividades. Foi preciso, semanalmente, acessar o ambiente virtual em sala de aula (utilizando internet particular e projetor), mostrar as atividades postadas, dialogar e fomentar a participação dos mesmos no ambiente virtual. Somente depois desse processo é que os alunos começaram a interagir de forma mais expressiva no ambiente virtual.

Concebida a importância da escrita para o desenvolvimento do pensamento matemático, que tipo de atividades você, professor, pode desenvolver para estimular a escrita dos seus alunos?

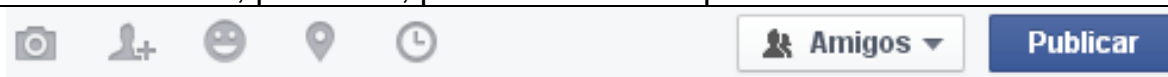

Quadro 7 - Reflexão para o professor/leitor. 
Fonte: Rovetta; Silva (2015, p. 27).

Além das atividades comentadas, o guia traz também sugestões de leituras e de mais atividades, em forma de anexos.

É compartilhando experiências que aprendemos e enriquecemos esse processo, por isso, ressaltamos a importância da produção do guia ao longo do desenvolvimento da pesquisa.

\section{Considerações finais e impactos do produto educacional}

A pesquisa, base para construção do produto educacional, foi rica em aspectos para discussão, sejam eles relacionados ao uso das redes sociais, à aprendizagem geométrica ou mesmo relacionados a questões metodológicas sobre esse processo. Observamos assim, que o tipo de prática desenvolvida exige uma postura dinâmica dos alunos e também do professor, sendo este um mediador durante o processo de interação dos alunos.

Constatamos também a importância de aspectos visuais no ensino da geometria, pois, mesmo na fase final do ensino médio, grande parte do público pesquisado ainda não tinha habilidades básicas de visualização desenvolvidas. Além disso, "a pesquisa traz indicativos de que, quando estabelecida uma conexão com as atividades desenvolvidas em sala de aula, a interação, a aprendizagem e o envolvimento dos alunos são satisfatórios" (ROVETTA, 2015, p. 12).

O produto educacional "Geometria nas redes sociais: custa essa ideia!" (ROVETTA; SILVA, 2015) representa, dessa forma, um veículo entre a pesquisa científica e o professor. Trata-se de um recurso para incitar reflexões sobre a prática e propor criação de novas atividades a partir das apresentadas. Dessa forma, o professor que está em sala de aula, por meio dos resultados da pesquisa apresentada no produto educacional, pode mudar sua prática, o que se reflete diretamente na aprendizagem do aluno. 
Com as atividades comentadas, foco do produto educacional criado, esperamos compartilhar nossa experiência e despertar o interesse dos professores para a adaptação ou elaboração de novas atividades que tenham como objetivo a construção do pensamento geométrico a partir da visualização. Reiteramos que essas atividades foram desenvolvidas com alunos da $3^{\underline{a}}$ série do ensino médio, porém reconhecemos que grande parte delas pode ser realizada também com alunos de outras séries do ensino médio e até mesmo das séries finais do ensino fundamental.

\section{Agradecimentos}

Agradecemos à escola e aos alunos que participaram da pesquisa, que subsidiou a construção do produto educacional apresentado neste texto. Somos gratas também ao programa Educimat, do Instituto Federal do Espírito Santo e a Fapes, pois a pesquisa esteve vinculada ao projeto intitulado Laboratório de Matemática do Ifes/Vitória: Atividades, Reflexões e Formação de Professores, aprovado pelo Edital Universal Individual 06/2014.

\section{Referências}

BAIRRAL, Marcelo Almeida. Discurso, interação e aprendizagem matemática em ambientes virtuais a distância. Rio de Janeiro: Edur, 2007.

BAIRRAL, Marcelo Almeida. Tecnologias da informação e comunicação na formação e Educação Matemática. Rio de Janeiro: Ed. da UFRRJ, 2009.

BORBA, Marcelo de Carvalho.; SILVA, Ricardo Scucuglia da Silva; GADANIDIS, George. Fases das tecnologias digitais em Educacação Matemática: sala de aula e internet em movimento. 1.ed. Belo Horizonte: Antência, 2014.

GUTIERREZ, Angel. Visualization in 3-dimensional geometry: in search of a framework. In: PUIG,L; GUTIÉRREZ, A. Proceedings of $20^{\text {th }}$ PME Conference, v.3, p.1926,Universidade de Valência, Spain, 1996.

KAPLÚN, Gabriel. Material educativo: experiência de aprendizado. Comunicação \& Educação, São Paulo, n. 27, maio/ago. 2003. p. 46-60.

NACARATO, Adair Mendes; SANTOS, Cleane Aparecida. Aprendizagem em Geometria na educação básica: a fotografia e a escrita na sala de aula. 1.ed. Belo Horizonte: 
Autêntica, 2014.

NASSER, Lilian. TINOCO, Lucia. Curso Básico de Geometria: formação de conceitos geométricos. Rio de Janeiro: Ed.IM/IFRJ, 2011.

ROVETTA, Organdi Mongin. Interações em sala de aula e em redes sociais no estudo de sólidos geométricos no ensino médio. 2015, 167f. Dissertação (Mestrado Profissional em Educação em Ciências e Matemática). Instituto Federal do Espírito Santo, Vitória, 2015.

ROVETTA, Organdi Mongin. SILVA, Sandra Aparecida Fraga da. Geometria nas redes sociais: curta essa ideia! Vitória: Edifes, 2015.

SALLES, Aline Terra; BAIRRAL, Marcelo Almeida. Identificando e analisando Heurísticas em interações no VMT-Chat. In: BAIRRAL, M.A. Pesquisa, ensino e inovação com tecnologias em educação matemática: de calculadoras a ambientes virtuais. 1. ed. Rio de Janeiro: EDUR, 2012. p. 117-139.

SEGADAS, Claudia. (Coor.). Visualizando Figuras Espaciais. Rio de Janeiro: IM/UFRJ, 2008. 